\title{
DETECTING SLUMS FROM QUICK BIRD DATA IN PUNE USING AN OBJECT ORIENTED APPROACH
}

\author{
Sulochana Shekhar \\ Central University of Karnataka, Gulbarga, India
}

WG, Theme or Special Session: VIII/8: Land

KEY WORDS: Slums, Quick bird data, Object oriented Analysis, eCognition, Pune

\begin{abstract}
:
We have been witnessing a gradual and steady transformation from a pre dominantly rural society to an urban society in India and by 2030 , it will have more people living in urban than rural areas. Slums formed an integral part of Indian urbanisation as most of the Indian cities lack in basic needs of an acceptable life. Many efforts are being taken to improve their conditions. To car ry out slum renewal programs and monitor its implementation, slum settlements should be recorded to obtain an adequate spatial data base. This can be only achieved through the analysis of remote sensing data with very high spatial resolution. Regarding the occurrences of settlement areas in the remote sensing data pixel-based approach on a high resolution image is unable to represent the heterogeneity of complex urban environments. Hence there is a need for sophisticated method and data for slum analysis. An attempt has been made to detect and discriminate the slums of Pune city by describing typical characteristics of these settlements, by using eCognition software from quick bird data on the basis of object oriented approach. Based on multi resolution segmentation, initial objects were created and further depend on texture, geometry and contextual characteristics of the image objects, they were classified into slums and non-slums. The developed rule base allowed the description of knowledge about phenomena clearly and easily using fuzzy membership functions and the described knowledge stored in the classification rule base led to the best classification with more than $80 \%$ accuracy.
\end{abstract}

\section{INTRODUCTION}

\subsection{Urbanisation and Slums}

Today, half the world's population lives in urban areas and by the middle of this century all regions will be predominantly urban, and according to current projections, virtually the whole of the world's population growth over the next 30 years will be concentrated in urban areas (UN-HABITAT, 2010). Above all, this rapid urban growth has been strongly associated with poverty and slum growth. It is felt that slums represent the worst of urban poverty and inequality. The increasing concentration of the urban population in slum areas is generally equated with increasing urban poverty a process recognized as the urbanization of poverty. According to new estimates presented in UN-HABITAT's report, between the year 2000 and 2010 over 200 million people in the developing world will have been lifted out of slum conditions. But in the course of the same years the number of slum dwellers will be increased by six million every year. Based on these trends it is expected that the world's slum population will continue to grow if no corrective action is taken in the coming years (UNHABITAT, 2010).

Defining slum raises several conceptual issues, making it difficult to precisely estimate the slum population living in urban areas. Concepts and definitions of slums vary from country to country and even in the same country, slum settlements may be known by different names (Kohli.D, 2011) In order to carry out the urban planning and development tasks necessary to improve living conditions for the poorest worldwide an adequate spatial data basis is needed (Mason, O.S and Fraser, C.S., 1998) and this can only be obtained through the analysis of remote sensing data (Hofmann,P.,2001). Since traditional methods demand more labour, money and time, alternative methods that include sophisticated techniques to extract the information from remote sensing data of very high resolution (VHR) and thus could reduce subjectivity, time and labour (Naga Jyothi., 2008 et al.) and provide more reliable data are need of the hour.

\subsection{Related work on detecting slums}

Many studies used census and field survey as the basis for studying about slums and formed the database for GIS-based mapping (Joshi Pratima, Sen Srinanda and Hobson Jane, 1998; Sliuzas and Kuffer, 2006). Recently very high resolution remote sensing based methods for mapping slums are getting popular among the scientific community (Mason\& Fraser, 1998; Sliuzas, Kerle and Kuffer, 2008; Hofmann .P., 2001; Hofmann. P., 2004 et al. ) but there are only very few studies based on Indian situation (Ujjwal Sur, 2004).

In most of the remote sensing based studies visual interpretation of data has played major role in identification of slums (Angeles et al., 2009; Sliuzas R.V 2004.,Sliuzas and Kuffer 2008; Baud, Kuffer, Pfeffer, Sliuzas, and Karuppannan (2010). Visual interpretation performed by interpreters familiar with local conditions provides a flexible and useful approach to slum mapping, though it does have shortcomings for repetitive surveys of very large cities due to difficulties in controlling quality over time and between interpreters. Later pixel based image classification is widely used in slum analysis and it also helped to understand the patterns over time and space (Jain, Sokhi and Sur, 2005; Jain, 2007; Weeks et al., 2007). But pixel-based approach on a high resolution image is unable to represent the heterogeneity of complex urban environments. In most cases by using only pixels' spectral information to 
describe the different types of settlements is insufficient due to variation in the structure, material, shape and so on. Hence more refined methods such as object oriented approaches are necessary to detect the informal settlements from very high spatial resolution data.

With the wide availability of VHR images, automatic object delineation techniques are being extensively researched and have proven to be accurate in urban applications (Ebert, Kerle, \& Stein, 2009; Sliuzas, Kerle, \& Kuffer, 2008). Recent developments in "object-oriented" image classification (based on image segmentation) have taken advantage of the detailed spatial characteristics of high-resolution datasets. The research in this area has emphasized the reduction of spectral variability within the objects and the incorporation of additional information from spatial and contextual image/ object characteristics (Johnsson, 1994; Blaschke and Strobl, 2001).

OOA is capable of using multiple data types during analysis to create meaningful segments. Segmentation is an important step preceding the classification of image objects. The classification process can include a variety of information, ranging from spectral mean values for each object, to measures of texture, context and shape. OOA offers great potential because of its ability to include spatial, spectral and contextual characteristics similar to human cognitive image interpretation (Hofmann, 2001; Herold et al, 2002; Van Der Sande et al., 2003; Benz et al., 2004).

Even though several studies showed the feasibility of detecting slums by using OOA, their relatively high inner-structural heterogeneity and their varying pattern impede the generation of an automated detection process. In the present paper, the visual interpretation indicators used by experts for slum identification and ground knowledge of slums in the city of Pune, India were used to semi-automate the classification in an OOA environment

\section{MATERIALS AND METHODS}

\subsection{Study area}

Pune the city (Figure1), selected for present study is one of the fast developing urban agglomerations in Asia.

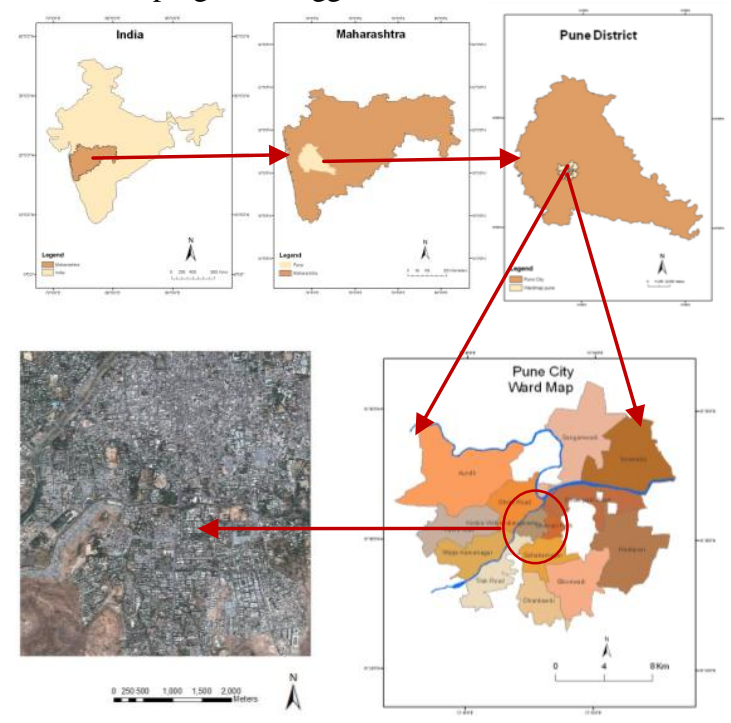

Figure 1.Location of Pune city and Quick Bird scene
It ranks eighth at national level and second at state of Maharashtra (Census of India, 2011). It has grown manifolds over the past two decades in terms of population and area. Pune city lies between latitudes $18^{\circ} 25^{\prime} \mathrm{N}$ and $18^{\circ} 37^{\prime} \mathrm{N}$ and longitudes between $73^{\circ} 44^{\prime} \mathrm{E}$ and $73^{\circ} 57^{\prime} \mathrm{E}$ and cover an area of 243.96 sq.km. Between 1976 and 1981 the population of Pune city (Table 1) grew by $16.7 \%$, from 1981 to 1991 it grew by $30.2 \%$, and between 1991 and 2001 growth increased to $62.17 \%$ (Shekhar., 2004;Shekhar.,2006). The recent census 2011 also showed decade growth rate of $22.6 \%$ (Census of India, 2011). India's Town and Country Planning Organization (TCPO), the technical arm of the ministry of urban development, ranks Pune as a city with third largest number of slums in India.

\begin{tabular}{|l|l|}
\hline Census year & Population \\
\hline 1951 & 400902 \\
\hline 1961 & 794052 \\
\hline 1971 & 1029466 \\
\hline 1981 & 1202848 \\
\hline 1991 & 1566651 \\
\hline 2001 & 2540069 \\
\hline 2011 & 3115431 \\
\hline
\end{tabular}

Source: Census of India

Table 1. Population of Pune city

Environment Status Report of Pune city for 2009-10 had stated that at the rate at which the slums in the city were growing, at least 50 per cent of the city's population would be living in slums. Pune slums are congested, have structures made of materials which are considered garbage, such as wood used for packing, plastic sheets, opened out metal tins, galvanised iron sheets, bamboo sheets, etc. and often lack the most basic of facilities for all its inhabitants. Pune's slum population is scattered across the whole city.

\subsection{Data base}

As data source Quick bird scene (60 $\mathrm{cm}$ spatial resolution) was used showing parts of Pune city (Figure 1).The image shows the central part of Pune city comprising typical urban features including slums and other formal areas. Cloud free Pan sharpened data with three bands (RGB) of the year 2006 was used for detecting slums from non-slum areas.

GIS layers of road and water bodies were also used as thematic layers in the object oriented analysis. Census data and Environmental Status reports of Pune city Municipal Corporation were used as secondary data for this study.

\subsection{Methodology}

The first step towards identifying the slums in OOA is to generate segments, i.e. an automatic division of an image into coherent groups of pixels (segments, objects) and the criteria used to segment an image is a degree of homogeneity within each particular object and heterogeneity among neighbouring objects (Baatz. M., A.Schape, 2000). It was done by using Multi resolution segmentation with the objective choice by using Estimating Scale Parameter (ESP) tool (Drăguţ et al., 2010). These outputs are called 'object primitives', which lead to meaningful 'objects of interest' by further refinement (e Cognition, 2010). The segmentation used all image layers as 
well as the thematic layer of road and water layer to create meaningful segments (Teo \&Chen, 2004). At the analysis level, a classification of the generated image objects follows and ends

in an iterative process of a knowledge-based object enhancement and (re-) classification.

As the main aim was the image-based detection and classification of slums (Figure 2), the first step was to understand the human interpretation process behind visual identification of slums and mimic these in Definiens Developer. The introduction of knowledge in the classification process would help to depose the difficulties of information extraction from very high spatial resolution images. In general, classification means to assign a number of objects to a certain class according to the class' description. Thereby class description is performed by describing typical properties or conditions the desired classes have. The objects then become assigned (classified) according to fulfilling or not these properties/conditions.

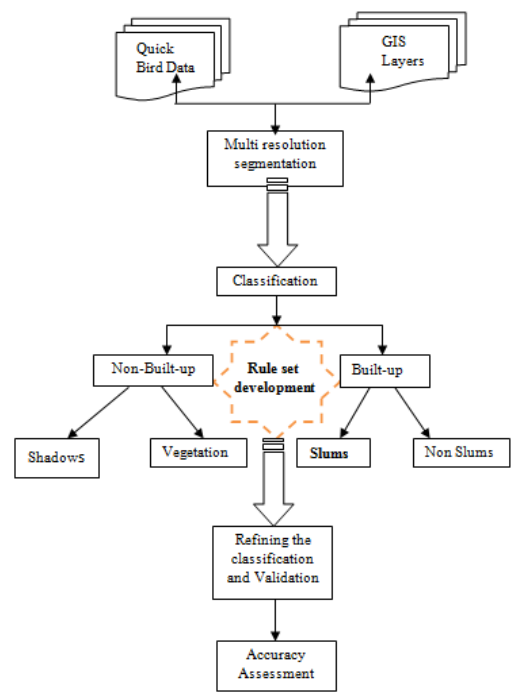

Figure 2 Flow Chart showing the methodology

\section{RESULTS AND DISCUSSIONS}

\subsection{Segmentation}

In order to receive image object primitives as basic processing units, the object oriented approach to image analysis needs a complete segmentation of an image. The term "segmentation" means: "an operation that creates new image objects or alters the morphology of existing image objects according to a given criteria" (Definiens, 2010). Image segmentation methods are split into two main domains: knowledge driven methods (topdown) vs. data driven methods (bottom-up). In comparison, the basic differences between both approaches are: top-down methods usually lead to local results because they just mark pixels or regions which meet the model description. In contrast, bottom-up methods perform a segmentation of the complete image. They are more grouping pixels to spatial clusters, which meet certain criteria of homogeneity and heterogeneity (Definiens, 2010). In the present case, both these approaches were used in Image segmentation. ESP tool was used to get the scale parameter as an objective choice instead of trial and error and with scale parameter of $40,0.5$ as shape/colour ratio and 0.5 for compact and texture ratio the multi-resolution segmentation was done for the whole image. All three bands (BGR) of quick bird data and the thematic layers (roads and water bodies) were used for image segmentation. The resulted objects were good enough to go for classification.

\subsection{Classification}

Feature recognition is an essential part of object-based image analysis. A comprehensive feature extraction methodology is the precondition for successful work with image objects. Given the large number of possible features for object description, it is necessary to identify the characteristic, significant features for object-classes of interest ( Nussbauma.S., et.al,2008)

In the present study in order to identify the slum areas, the following factors were considered for classification:

$\checkmark$ Small sized structures with high density

$\checkmark$ Tone difference in the slum areas

$\checkmark$ Irregular internal street pattern

$\checkmark$ Less/no vegetation/green in slum areas

$\checkmark$ Areas of wastelands, such as on banks of Rivers or Canal, along railway line and road margin were taken as association for identification.

In Pune, the existing slum locations (Table 2, Figure 3) have formed the basis of identification of these factors.

\begin{tabular}{|l|c|}
\hline Location & $\begin{array}{l}\text { Number of } \\
\text { Hutments }\end{array}$ \\
\hline River banks & 5142 \\
\hline $\begin{array}{l}\text { Along Small streams } \\
\text { and canals }\end{array}$ & 19670 \\
\hline Hill and Hill slopes & 11604 \\
\hline $\begin{array}{l}\text { Roadsides and } \\
\text { places Meant for } \\
\text { Public use }\end{array}$ & 3584 \\
\hline
\end{tabular}

Source: Environmental Status Report, 2006-2007

Table 2. Location of slums in Pune city

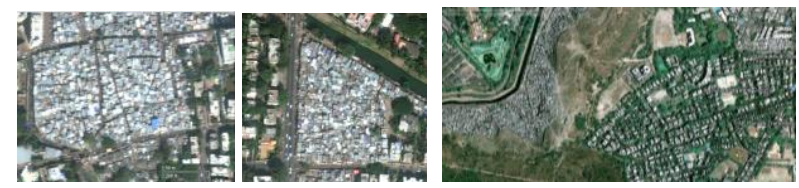

Figure 3. Location of Slums near canal and along the hill slopes

The image classification in e Cognition is based on userdefined fuzzy class descriptions of spectral, spatial and contextual features. The classification started with assigning image objects to roads and water bodies. In the absence of NIR band, using thematic layer to classify the image objects as water bodies helped to reduce the false positives as well as further refining the rule set. Since majority of the slums are located near the water bodies and along the road, railway line sides, classifying these objects in turn helped to detect the location of slums.

Classification of non-built-up area such as Shadows and vegetation was carried out by using brightness values and 
green ratio. Shadow of the trees and buildings could be detected using the low values of brightness and mean difference to scene. Shadows were used as a proxy for height information in the absence of DSM. The high rise buildings in planned areas exhibited clear shadows (NB1) compared to narrow or negligible shadows of slum buildings. Vegetation (NB2) was classified using the customized arithmetic ratio values (green ratio i.e., green / blue + green + red). These classes were useful in defining contextual relationships for characterization of built-up.

Classification of non-built-up area is followed by classification of built-up area. In high-resolution satellite images, a very salient feature of urban scenes is that they are highly textured. It is therefore adequate to use the texture features of the image as a measure to classify the image (Shan Yu and Berthod, M. and Giraudon, G, 1999). Texture based measures such as Grey Level Co-occurrence Matrix (GLCM) Entropy (quick8/11) of blue and red bands was used to classify built-up. GLCM is a tabulation of how often different combinations of pixel brightness values (grey levels) occur in an image (Definiens, 2009). The quick (8/11) is a performance optimization version and works only on data with a bit depth of 8 or 11 bits. The entropy tells how the elements are distributed in a given space. If the elements of GLCM are distributed equally, then the value for entropy is high. Hence in the present case, GLCM entropy value of above 4.1 in the blue band was used to classify the image objects into built-up (Figure 4). The classified built-up objects are again refined by using the entropy value less than 3.8 in band 3 .

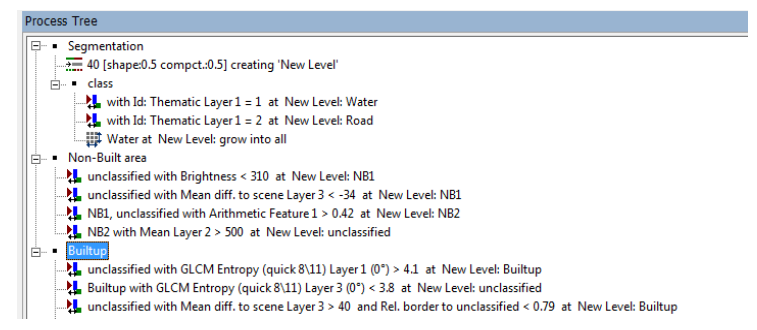

Figure 4. Rule set for classification

\subsection{Separation of slums and non-slums}

Non Slum areas display different characteristics than slum areas. A combination of spectral, morphological and contextual information was used to classify non-slum (formal) areas. The association with vegetation and shadow were important indicators for separation. A sequence of steps involving brightness, layer means, texture and distance to features was used to further refine the classification. The mean layer intensity values of an image object in blue and green bands were used to separate the non-slum built up from other built up area. The formal built-up objects are having higher value in these two layers than other built up objects. Similarly the formal built-up objects are brighter than other built up due to the construction materials; so, brightness feature was used to separate formal from informal (Slums).

When classifying a satellite image, the class assigned to an object depends not only on the spectral feature of the object itself, but also on the spectral feature of its neighbours. In this context, spectral characteristics of Image such as GLCM Texture measures also used to separate the formal from Informal. GLCM Contrast of band 3 was used for this purpose.
The contextual information was used to separate non-slum built-up objects from Slum (informal) objects. Hence the feature Rel. Border was used to determine the relative border length of formal built-up object shares with the NB2 and NB1 (Green vegetation and Shadow in Figure 5) image objects. It describes the ratio of the shared border length of an image object (with a neighboring image object assigned to a defined class) to the total border length. If the relative border of an image object to image objects of a certain class is 1 , the image object is totally embedded in them. If the relative border is 0.5 then the image object is surrounded by half of its border. The relative border length can only be expressed in pixels. The relative border value of above 0.399 was used to separate formal built-up from Informal built-up objects.

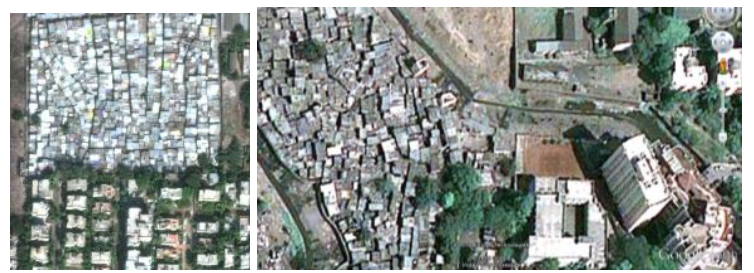

Figure 5. Proximity of vegetation and shadow in built-up which differentiate between slum and non-slum areas

When contextual information is used at the object level, it can be used in association with common-sense knowledge to obtain a coherent interpretation of the whole scene or to aid in detecting less obvious objects. Mostly slums are tends to be located near vulnerable areas like close to river and transportation lines (Figure $3 \& 6$ ). Therefore Distance to water (River, canal) and roads features were also used to separate and refine the formal built-up areas.
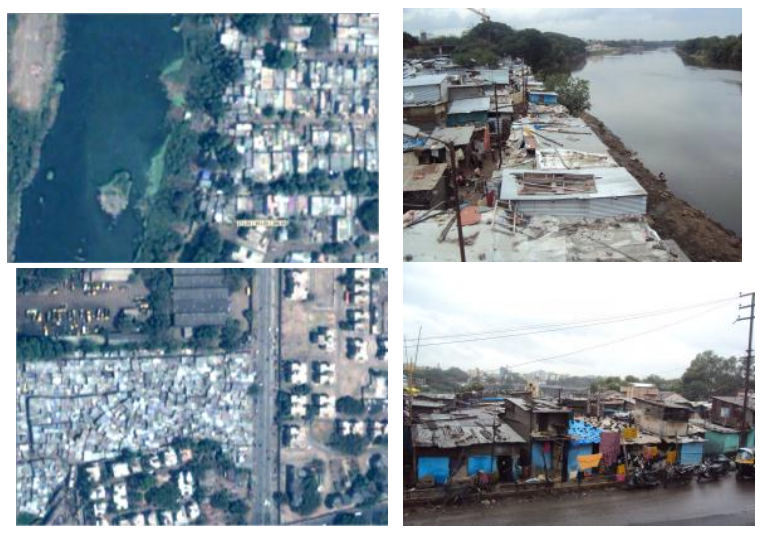

Figure 6. location of slums with field photos
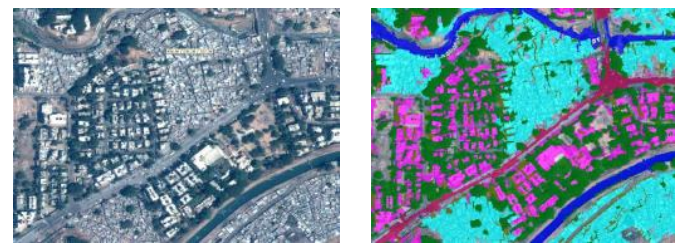

Figure 7. Slum classification

After separating the formal areas, the remaining built-up was classified as slums. The built-up other than formal was first merged, so that geometry of the objects can be better 
understood. Since the informal settlements tend to cluster themselves, it can be differentiated easily from other formal areas based on their area. Therefore 'area' feature was used to identify the slums in eCognition environment. The false positives i.e., non-slum areas looking like slums were eliminated by using adequate rules sequentially. The false positives are happening because of non-visible slums exemplified by planned but deteriorating inner cities (Turkstra, 2008). The false positives were reclassified into non-slum areas, by using geometry of the object such as area, asymmetry, shape index and also contextual parameters such as distance to the object. Similarly some slum areas which were surrounded by non-slum areas also included in non-slum areas. To rectify this, relation to the border of the object and distance to parameters were used. So that the slums which included in non-slum areas were classified correctly Thus finally the image was classified (figure 8) into slums and non-slums along with other non- built-up areas.

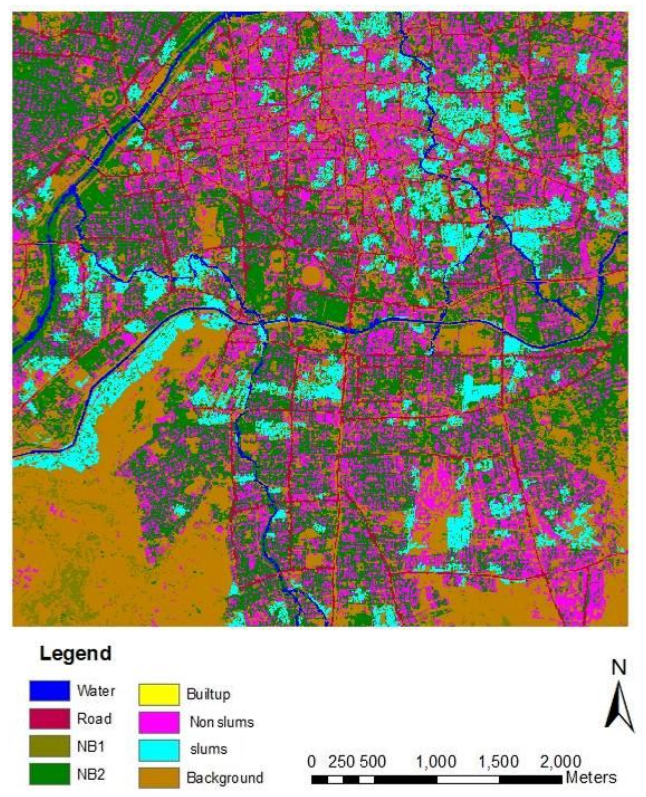

Figure 8. Classified Image of central part of Pune city

\subsection{Accuracy assessment}

The evaluation of a classification is a complex concept that includes the reference to several criteria. The main idea is to determine the accuracy of this classification by comparing the results with data provided from the reality in the field. These realities come from the slum survey carried out by city based NGO's and Pune Municipal Corporation's environmental status report(2010).

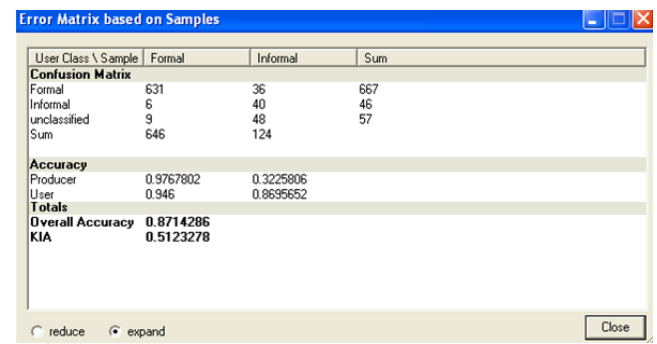

Figure 9. Accuracy assessment
Through field survey and primary data collected from slum dwellers, the slum map was created. The classification result was compared with slum map prepared based on Slum Survey. The overall accuracy is $87 \%$ (Figure 9).

\section{CONCLUSION}

The issue of slums is very complex. Detecting slums might be one of the most challenging tasks within urban remote sensing. Though the present study demonstrated the advantage of VHR data and OOA approach in detecting the slums, it required local knowledge of existing slums and their characteristics. Using thematic layers such as roads and water bodies saved the time and reduced the complexity of rule set on extracting roads and water bodies from the image and thus helped to concentrate on detecting and discriminating slums from nonslums. One major issue in this analysis is false positives. Thorough understanding of study area is essential to develop the rule set to diminish the false positives. Detailed field visit is also essential to develop the rule set and can help to achieve reasonable accuracy. But complete removal of false positives is not possible in the inner/old city area because of its complexity. The present study area is mainly covering the indigenous city of Pune. So, complete clean-up was not possible and not done in the present study.

Applying the same rule set to other scenes of quick bird data was also tried and the results are promising. But the threshold values for various rules such as brightness values, GLCM values etc. have to be modified as per the scene characteristics. Thus the present work may provide a basis for more advanced research to generalise a rule set which can be applied to various scenes of the same city and to various cities.

\section{ACKNOWLEDGEMENTS}

The author would like to thank Dr. Richard Sliuzas and Dr. Norman Kerle of ITC-Faculty of Geoinformation Science \& Earth Observation, University of Twente, The Netherlands for their continuous support and valuable inputs during this work. Special thanks to Divyani Kohli and Deepti Durgi, (Ph.D scholars, ITC) for assisting in learning the eCognition software and sharing the Quickbird data. Sincere thanks to European Commission for providing Post Doctoral Research Fellowship to complete this work.

\section{References}

Angeles, G., Lance, P., Barden-O'Fallon, J., Islam, N., Mahbub, A. Q. M., \& Nazem, N. I. (2009). The 2005 census and mapping of slums in Bangladesh: design, select results and application. [Article]. International Journal of Health Geographics, 8, 19.

Baud, I., Kuffer, M., Pfeffer, K., Sliuzas, R., \& Karuppannan, S. (2010). Understanding heterogeneity in metropolitan India: The added value of remote sensing data for analyzing substandard residential areas. International Journal of Applied Earth Observation and Geoinformation, 12(5), 359-374.

Baud, I., Pfeffer, K., Sridharan, N., \& Nainan, N. (2009). Matching deprivation mapping to urban governance in three Indian mega-cities. Habitat International, 33(4), 365-377. 
Baud, I., Sridharan, N., \& Pfeffer, K. (2008). Mapping urban poverty for local governance in an Indian mega-city: The case of Delhi. Urban Studies, 45(7), 1385-1412.

Baatz, M. and scha“ pe, A.,(2000). Multiresolution segmentation - an optimization approach for high quality multi-scale image segmentation. J. Strobl, T. Blaschke and G. Griesebner (Eds) (Heidelberg, Germany: Wichmann Verlag)

Blaschke, T. (2010). Object based image analysis for remote sensing. ISPRS Journal of Photogrammetry and Remote Sensing, 65, 2-16.

Cleve, C., Kelly, M., Kearns, F. R., \& Moritz, M. (2008). Classification of the wildland-urban interface: A comparison of pixel- and object-based classifications using high-resolution aerial photography. Computers, Environment and Urban Systems, 32(4), 317-326.

Census of India(2011), Government of India.

Definiens. (2009). Definiens eCognition Developer 8 User Guide.

Drăguţ, L., Tiede, D., \& Levick, S. R. (2010). ESP: a tool to estimate scale parameter for multiresolution image segmentation of remotely sensed data. International Journal of Geographical Information Science, 24(6), 859 - 871.

EGM.,(2008), Expert group Meeting,2008, organized by UNHABITAT , 21-23 May 2008 at ITC, Enschede, The Netherlands

Hofmann, P. (2001). Detecting Informal Settlements from Ikonos Image Data Using Methods of Object Oriented Image Analysis-An Example from Cape Town (South Africia) Paper presented at the Remote Sensing of Urban Areas.

Hofmann, P., Strobl, J., Blaschke, T., \& Kux, H. (2008). Detecting informal settlements from Quickbird data in Rio De Janeiro using an object based approach. Object-based Image Analysis, 531-553.

Jain, S. (2007). Use of IKONOS satellite data to identify informal settlements in Dehradun, India. International Journal of Remote Sensing, 28(15), 3227 - 3233.

Jain, S., Sokhi, B. S., \& Sur, U. (2005). Slum identification using high-resolution satellite data. GIM International, 19(9).

Joshi, P., Sen, S., \& Hobson, J. (2002). Experiences with surveying and mapping Pune and Sangli slums on a geographical information system (GIS). Environment and Urbanization, 14(2), 225-240.

Kohli, D., et al. An ontology of slums for image-based classification. Computers, Environment and Urban Systems (2011).

Mason, S. O., \& Fraser, C. S. (1998). Image sources for informal settlement management. The Photogrammetric Record, 16(92), 313-330.

Naga Jyothi. B, Babu. G.R and Murali Krishna. I.V (2008) Object Oriented and Multi-Scale Image Analysis: Strengths,
Weaknesses, Opportunities and Threats-A Review, Journal of Computer Science 4 (9): 706-712, 2008.

Nussbauma.S , Niemeyerb.I , . Cantya M.J (2008) Seath - a new tool for automated feature extraction in the context of object-based image analysis.

PMC ,(2010) Pune Municipal Corporation Environmental Status Report -2010 .

Sen, S., Hobson, J., \& Joshi, P. (2003). The Pune Slum Census: creating a socio-economic and spatial information base on a GIS for integrated and inclusive city development. [Proceedings Paper]. Habitat International, 27(4), 595-611.

Shekhar, S. (2004). Urban sprawl assessment - entropy approach. 8(5), 43-48

Shekhar, S. (2006). Modelling Urban Development with Fuzzy Logic and cellular automata. Asian Journal of Geoinformatics, Vol 6 No 1 2006. Page 3-10.

Sliuzas, R.V., 2004. Managing informal settlements: a study using geo-information in Dar es Salaam,

Tanzania. Utrecht University, ITC Publication Series No. 112

Sliuzas, R.V., 2008. Improving the performance of urban planning and management with remote sensing systems. In: C. Jurgens (Editor), Remote sensing : new challenges of high resolution - EARSeL workshop, Bochum, Germany.

Sliuzas, R. V., Kerle, N., \& Kuffer, M. (2008). Object-oriented mapping of urban poverty and deprivation. Paper presented at the EARSeL worshop on Remote Sensing for Developing Countries in Conjunction with GISDECO 8.

Sliuzas, R. V., \& Kuffer, M. (2008). Analysing the spatial heterogeneity of poverty using remote sensing : Typology of poverty areas using selected RS based indicators. Paper presented at the EARSeL Workshop on Remote Sensing.

Teo, T. A., \& Chen, L. C. (2004). Object-Based Building Detection from LIDAR Data and High Resolution Satellite Imagery Paper presented at the 25th Asia Conference on Remote Sensing.

Turkstra, J., 2008, Visible and non-visible slum, Libya and Somalia, Paper presented at the Expert Group Meeting on Slum Mapping at ITC in Enschede Netherlands, 2123May2008. Available online at http://www.ciesin.columbia.edu/confluence/

Ujjwal Sur, Sadhana Jain, B. S. Sokhi.,2004, Identification / Mapping of Slum Environment using IKONOS Satellite Data: A Case Study of Dehradun, India,

http://www.gisdevelopment.net/application/environment/pp/mi 04011.htm

UN-HABITAT. (2010). State of World's Cities 2010/2011:

United Nations Human Settlements Programme (UNHABITAT).

Weeks, J., Hill, A., Stow, D., Getis, A., \& Fugate, D. (2007). Can we spot a neighborhood from the air? Defining neighborhood structure in Accra, Ghana. GeoJournal, 69(1), 922. 